\title{
BRIEF COMMUNICAITON
}

\section{Lisdexamfetamine to improve excessive daytime sleepiness and weight management in narcolepsy: a case series}

\author{
Ana C. Aguilar, ${ }^{1}$ Cristina Frange, ${ }^{2}$ Lucio H. Pimentel Filho, ${ }^{1}$ Maria J. Reis, ${ }^{1}$ Sergio Tufik, ${ }^{1}$ \\ Fernando M.S. Coelho ${ }^{1,2}$ iD \\ ${ }^{1}$ Departamento de Psicobiologia, Universidade Federal de São Paulo (UNIFESP), São Paulo, SP, Brazil. ${ }^{2}$ Departamento de Neurologia e \\ Neurocirurgia, UNIFESP, São Paulo, SP, Brazil.
}

\begin{abstract}
Objective: To report the successful use of lisdexamfetamine in the management of narcolepsy. Methods: Five narcoleptic patients received lisdexamfetamine, at different dosages and for different periods, for management of excessive daytime sleepiness and weight control.

Results: All patients experienced improvement of excessive daytime sleepiness and lost weight without side effects.

Conclusion: Lisdexamfetamine appears promising for the treatment of two of the most common symptoms of narcolepsy: excessive daytime sleepiness and weight gain.
\end{abstract}

Keywords: Sleep; excessive daytime sleepiness; weight gain; obesity; narcolepsy; lisdexamfetamine

\section{Introduction}

Narcolepsy is a rare hypothalamic disease and sleep disorder characterized by excessive daytime sleepiness (EDS) and uncontrollable episodes of falling asleep regardless of the circumstances. ${ }^{1}$ Other symptoms include abnormalities during the rapid eye movement (REM) stage of sleep, such as cataplectic attacks, sleep paralysis, and hypnagogic and hypnopompic hallucinations. ${ }^{1,2}$ Disease onset is characterized by a bimodal distribution, usually starting around adolescence or early adult life, but with the potential to occur at any age. ${ }^{3-5}$ According to the International Classification of Sleep Disorders, 3rd edition (ICSD3), narcolepsy type 1 (NT1) is characterized by excessive daytime sleepiness, hypocretin deficiency syndrome, and signs of REM-sleep dissociation (e.g., cataplexy, hypnagogic and hypnopompic hallucinations, sleep paralysis). Narcolepsy type 2 (NT2) is characterized by excessive daytime sleepiness and abnormal manifestations of REM sleep on polysomnography/multiple sleep latency test (MSLT); cataplexy must be absent and the CSF hypocretin-1 concentration must be greater than $110 \mathrm{pg} / \mathrm{mL}^{6}{ }^{6}$

The pathophysiology of the selective loss of hypocretinergic neurons is uncertain, but inflammatory/autoimmune processes appear to be substantially involved. EDS represents the most common and disabling symptom, with episodes of irresistible, typically short and restorative sleep attacks. ${ }^{7,8}$

Correspondence: Fernando Morgadinho Santos Coelho, Departamento de Psicobiologia, Universidade Federal de São Paulo (UNIFESP), Rua Napoleão de Barros, 625, Vila Clementino, CEP 04024-002, São Paulo, SP, Brazil.

E-mail: fernandomorgadinho@ hotmail.com

Submitted May 09 2019, accepted Sep 05 2019, Epub Dec 202019.
Narcolepsy has a major impact on the activities of daily living. ${ }^{9}$ These patients experience many limitations and difficulties, especially in daytime activities such as school, work, interpersonal relationships, and social activities. ${ }^{10}$ This decreases quality of life and is associate with a higher risk of accidents in situations requiring attention, such as driving or manual labor. ${ }^{11}$

The primary objective of narcolepsy management should be to alleviate daytime sleepiness and restore the patient's function as close to normal as possible at school, at work, at home, and socially. ${ }^{12}$

The first-line of therapy for EDS in narcolepsy consists of psychostimulants and sodium oxybate. ${ }^{13}$ In some cases, EDS may persist despite treatment, especially when adverse effects occur and optimal dose titration is difficult. In addition, critical concerns such as weight gain leading to obesity affect about $30 \%$ of narcolepsy patients. $^{14}$

Few medications have been approved to treat EDS; these include methylphenidate, amphetamines, modafinil, and sodium oxybate. ${ }^{15}$ Others have not been approved for this indication but are prescribed off-label, such as lisdexamfetamine. Although this central nervous system stimulant has not been approved by regulatory agencies for narcolepsy, it has been used to managing narcolepsy symptoms with good tolerability. ${ }^{16}$ Lisdexamfetamine dimesylate is a prodrug of dextroamphetamine which permits once-daily oral administration. It is not recommended for

How to cite this article: Aguilar AC, Frange C, Pimentel Filho LH, Reis MJ, Tufik S, Coelho FMS. Lisdexamfetamine to improve excessive daytime sleepiness and weight management in narcolepsy: a case series. Braz J Psychiatry. 2020;42:314-316. http://dx. doi.org/10.1590/1516-4446-2019-0544 
weight loss as monotherapy, but has been used for this purpose. $^{17}$

As sodium oxybate has not yet been approved by the Brazilian Health Surveillance Agency (ANVISA), pharmacotherapeutic options for treatment of narcolepsy are limited in the country. We report a series of five patients with narcolepsy who started lisdexamfetamine after failure of modafinil and methylphenidate and describe the potential of this agent for management of EDS and narcolepsy-associated obesity.

\section{Case series}

This report describes five patients treated at the Universidade Federal de São Paulo Outpatient Excessive Daytime Sleepiness Clinic. All patients (four women and one man, ages 22-51 years) met ICSD-3 diagnostic criteria for narcolepsy, including an average sleep latency of $\leqslant 8$ minutes and presence of two or more episodes of sleep-onset REM periods (SOREMP). ${ }^{18}$ Two cases were classified as NT1 and three as NT2; CSF hypocretin-1 levels were measured in four of the five patients (Table 1). All patients had been taking stimulant medication (methylphenidate or modafinil) for treatment of EDS for at least 3 months and were on stable doses. The decision to start lisdexamfetamine was prompted by refractory EDS in all cases. The dosage was individualized, but generally did not exceed $50 \mathrm{mg}$.

The duration of lisdexamfetamine therapy ranged from 2 to 20 months (median, 3 months). Each patient had EDS quantified by the Epworth Sleepiness Scale (ESS) before and after initiation of lisdexamfetamine.

Patient \#1 was a 28-year-old male with NT2 and a history of restless legs syndrome. Lisdexamfetamine was administered for 2 months at a dosage of $50 \mathrm{mg}$ in the morning, with improvement in somnolence and slight weight loss (Table 1).

Patient \#2 was a 22-year-old female with NT2 and a history of restless legs syndrome. Lisdexamfetamine was administered for 3 months at a dosage of $50 \mathrm{mg}$ in the morning, with improvement in somnolence and progressive weight loss (Table 1).

Patient \#3 was a 27-year-old female with NT2. Lisdexamfetamine was given for 5 months at a dosage of $50 \mathrm{mg}$ in the morning, with improvement in EDS, reductions in appetite and sugar cravings, and progressive weight loss (Table 1).
The only patient who gained weight was patient \#4, a 51-year-old postmenopausal female with NT1. Lisdexamfetamine was administered for 2 months at a dosage of $30 \mathrm{mg} /$ day, also in the morning. At the start of treatment, patient \#4 reported a reduction in appetite, but at her last visit, 2 months after starting lisdexamfetamine, she reported increased appetite resulting in weight gain. Curiously, she was the only patient whose daytime sleepiness decreased only slightly (ESS: 23 at baseline vs. 20 after treatment), with no clinical relevance. In addition, she reported an increase in hallucinations, asthenia, occasional chest pain, and generalized malaise.

Patient \#5 was a 44-year-old female with NT1 and a history of polycystic ovary syndrome. Lisdexamfetamine was administered for 20 months at a dosage of $50 \mathrm{mg}$ in the morning, combined with citalopram $20 \mathrm{mg} /$ day. EDS improved and there was progressive weight loss (Table 1). One month after initiation of lisdexamfetamine, patient \#5 reported psychomotor slowing, which resolved spontaneously. This patient had the longest duration of lisdexamfetamine therapy (20 months) and lost the most weight (down to $85 \mathrm{~kg}$ after treatment from $101 \mathrm{~kg}$ at baseline). Her ESS score also improved markedly, from 15 at baseline to 5 after treatment.

Overall, all five patients in this series reported improvement of EDS. ESS scores decreased from a mean of 18.2 at baseline to 10.8 after at least 8 weeks of lisdexamfetamine treatment (Table 1). During the evaluation period, all patients reported appetite reduction; four experienced weight loss and one experienced weight gain.

Regarding safety, irritability was reported by two of the five patients in this series; one complained of psychomotor slowing, disconnected thinking, and headache. One patient denied any adverse effects and, in fact, reported improvement in anxiety symptoms.

\section{Ethics statement}

This investigation was approved by the ethics committee of Universidade Federal de São Paulo (CEP/UNIFESP 3348735, project 0286/2019, CAAE 0182119.1.0000. 5505).

\section{Discussion}

In our case series, lisdexamfetamine improved EDS as soon as the first month of use and up to 20 months after

Table 1 Clinical characteristics of the sample before and after intervention with lisdexamfetamine

\begin{tabular}{|c|c|c|c|c|c|c|c|c|c|c|c|c|}
\hline \multirow[b]{2}{*}{ Patient } & \multirow[b]{2}{*}{ Age } & \multirow[b]{2}{*}{ Gender } & \multirow{2}{*}{$\begin{array}{l}\text { Narcolepsy } \\
\text { type }\end{array}$} & \multirow{2}{*}{$\begin{array}{l}\text { HCT-1 } \\
(\mathrm{pg} / \mathrm{mL})\end{array}$} & \multirow[b]{2}{*}{ SOREMP } & \multirow{2}{*}{$\begin{array}{l}\text { MSLT } \\
\text { (mins) }\end{array}$} & \multirow{2}{*}{$\begin{array}{l}\text { Maximum } \\
\text { dose (mg) }\end{array}$} & \multirow{2}{*}{$\begin{array}{c}\text { Treatment } \\
\text { duration (months) }\end{array}$} & \multicolumn{2}{|c|}{$\begin{array}{c}\text { BMI } \\
\left(\mathrm{kg} / \mathrm{m}^{2}\right)\end{array}$} & \multicolumn{2}{|c|}{$\begin{array}{c}\text { Epworth } \\
\text { Sleepiness Scale }\end{array}$} \\
\hline & & & & & & & & & Pre & Post & Pre & Post \\
\hline \#1 & 28 & $M$ & 2 & 350 & 2 & $7^{\prime}$ & 50 & 2 & 28.4 & 27.7 & 19 & 10 \\
\hline \#2 & 22 & $\mathrm{~F}$ & 2 & 305 & 4 & $1^{\prime} 48^{\prime \prime}$ & 50 & 3 & 28.8 & 26.8 & 19 & 8 \\
\hline \#3 & 27 & $\mathrm{~F}$ & 2 & NM & 2 & $8^{\prime}$ & 50 & 5 & 28 & 24 & 15 & 11 \\
\hline \#4 & 51 & $\mathrm{~F}$ & 1 & 58 & 3 & $1^{\prime} 5^{\prime \prime}$ & 30 & 2 & 26.6 & 28.2 & 23 & 20 \\
\hline \#5 & 44 & $\mathrm{~F}$ & 1 & 40 & 4 & $5^{\prime}$ & 50 & 20 & 36.2 & 30.4 & 15 & 5 \\
\hline
\end{tabular}

$\mathrm{BMI}=$ body mass index; $\mathrm{F}$ = female; HCT-1 = hypocretin-1; $\mathrm{M}=$ male; MSLT = multiple sleep latency test; NM = not measured; SOREMP = sleep-onset rapid eye movement episodes.

Epworth Sleepiness Scale scores range from 0-24; 0-9 indicates no sleepiness symptoms, while > 10 indicates daytime sleepiness. 
initiation of therapy, as well as reduced appetite and promoted weight loss.

Patients with narcolepsy have several clinical comorbidities, but weight gain is particularly common, often leading to obesity (30\% of cases). This, in turn, is associated with the metabolic syndrome and increased cardiovascular risk, which can significantly reduce quality of life and increase morbidity and mortality. Evidence suggests that narcolepsy is associated with weight gain regardless of disease duration or type. ${ }^{14,19,20}$ Reduced hypocretin levels, basal metabolism, and physical activity can explain this finding at least partly; narcoleptic patients are at $50 \%$ higher risk of developing overweight and obesity than the general population. ${ }^{21}$ In addition, weight gain may be related to an increasing and alarming prevalence of eating disorders, with $50 \%$ of narcoleptic patients reporting constant food cravings and an increased prevalence of binge eating. ${ }^{22,23}$ The mechanisms underlying weight gain in narcolepsy are still unknown, and we hope these reflections will help drive a new line of research into this rare and disabling disease.

Although the small sample size precluded any statistical comparisons, this series suggest that lisdexamfetamine is well tolerated and can be an option for management of EDS and body weight in patients with narcolepsy.

An additional limitation of this study was its retrospective approach. However, there are no other published data on lisdexamfetamine as an option to treat EDS in narcolepsy. Large, randomized trials are needed to validate our empirical observations. Ideally, such studies would include dietary recalls, investigation of eating habits, and bioelectrical impedance assessment of body composition. Positive findings could lead to a formal indication of lisdexamfetamine as an alternative treatment option for EDS and obesity in patients with narcolepsy.

\section{Acknowledgements}

This study received financial support from Associação Fundo de Incentivo à Pesquisa (AFIP) and São Paulo Research Foundation (FAPESP) (grant \# 2018/18952-1 to $\mathrm{CF}$ ).

\section{Disclosure}

The authors report no conflicts of interest.

\section{References}

1 Mitler MM, Hajdukovic R, Erman M, Koziol JA. Narcolepsy. J Clin Neurophysiol. 1990;7:93-118.

2 Nishino S. Clinical and neurobiological aspects of narcolepsy. Sleep Med. 2007;8:373-99.
3 Dauvilliers Y, Montplaisir J, Molinari N, Carlander B, Ondze B, Besset A, et al. Age at onset of narcolepsy in two large populations of patients in France and Quebec. Neurology. 2001;57:2029-33.

4 Wing YK, Chen L, Fong SY, Ng MH, Ho CK, Cheng SH, et al. Narcolepsy in Southern Chinese patients: clinical characteristics, HLA typing and seasonality of birth. J Neurol Neurosurg Psychiatry. 2008;79:1262-7.

5 Won C, Mahmoudi M, Qin L, Purvis T, Mathur A, Mohsenin V. The impact of gender on timeliness of narcolepsy diagnosis. J Clin Sleep Med. 2014;10:89-95.

6 Ruoff C, Rye D. The ICSD-3 and DSM-5 guidelines for diagnosing narcolepsy: clinical relevance and practicality. Curr Med Res Opin. 2016;32:1611-22.

7 Jimenez-Correa U, Haro R, Obdulia Gonzalez R, Velazquez-Moctezuma J. Correlations between subjective and objective features of nocturnal sleep and excessive diurnal sleepiness in patients with narcolepsy. Arq Neuropsiquiatr. 2009;67:995-1000.

8 Wozniak DR, Quinnell TG. Unmet needs of patients with narcolepsy: perspectives on emerging treatment options. Nat Sci Sleep. 2015;7: 51-61.

9 Raggi A, Plazzi G, Ferri R. Health-related quality of life in patients with narcolepsy: a review of the literature. J Nerv Ment Dis. 2019;207:84-99.

10 Szakacs A, Chaplin JE, Tideman P, Strömberg U, Nilsson J, Darin $\mathrm{N}$, et al. A population-based and case-controlled study of children and adolescents with narcolepsy: health-related quality of life, adaptive behavior and parental stress. Eur J Paediatr Neurol. 2019;23:288-95.

11 Tzeng NS, Hsing SC, Chung CH, Chang HA, Kao YC, Mao WC, et al. The risk of hospitalization for motor vehicle accident injury in narcolepsy and the benefits of stimulant use: a nationwide cohort study in Taiwan. J Clin Sleep Med. 2019;15:881-9.

12 Krahn LE, Hershner S, Loeding LD, Maski KP, Rifkin DI, Selim B, et al. Quality measures for the care of patients with narcolepsy. J Clin Sleep Med. 2015;11:335.

13 Scammell TE. Narcolepsy. N Engl J Med. 2015;373:2654-62.

14 Kotagal S, Krahn LE, Slocumb N. A putative link between childhood narcolepsy and obesity. Sleep Med. 2004;5:147-50.

15 Bhattarai J, Sumerall S. Current and future treatment options for narcolepsy: a review. Sleep Sci. 2017;10:19-27.

16 Thorpy MJ. Update on therapy for narcolepsy. Curr Treat Options Neurol. 2015;17:347.

17 U.S. National Library of Medicine, National Center for Biotechnology Information. Compound summary: Lisdexamfetamine [Internet]. 2016 [cited 2019 Oct 04]. https://pubchem.ncbi.nlm.nih.gov/compound/ Lisdexamfetamine.

18 Pataka AD, Frangulyan RR, Mackay TW, Douglas NJ, Riha RL. Narcolepsy and sleep-disordered breathing. Eur J Neurol. 2012;19: 696-702.

19 Schuld A, Hebebrand J, Geller F, Pollmacher T. Increased bodymass index in patients with narcolepsy. Lancet. 2000;355:1274-5.

$20 \mathrm{Um} \mathrm{YH}$, Kim TW, Jeong JH, Seo HJ, Han JH, Kim SM, et al. A Longitudinal follow-up study on multiple sleep latency test and body mass index of patients with narcolepsy type 1 in Korea. J Clin Sleep Med. 2017;13:1441-4.

21 Cremaschi RC, Hirotsu C, Tufik S, Coelho FM. Narcolepsy type 1 and type 2 - a 10-year follow-up: body mass index and comorbidities. Sleep Med. 2017;32:285-6.

22 Chabas D, Foulon C, Gonzalez J, Nasr M, Lyon-Caen O, Willer JC, et al. Eating disorder and metabolism in narcoleptic patients. Sleep. 2007;30:1267-73.

23 Fortuyn HA, Swinkels S, Buitelaar J, Renier WO, Furer JW, Rijnders $\mathrm{CA}$, et al. High prevalence of eating disorders in narcolepsy with cataplexy: a case-control study. Sleep. 2008;31:335-41. 